\title{
Audit Pemasaran Pada Multi Level Marketing Forever Young DC-339 Lumajang - Jawa Timur
}

\author{
Yudiyanto Joko Purnomo \\ Fakultas Ekonomi, Universitas Nasional Pasim, Indonesia \\ Email corresponding author: joko.jember2015@gmail.com
}

\begin{abstract}
ABSTRAK
Penelitian ini bertujuan untuk melihat pengembangan manajemen Network yang nantinya dapat dilihat dari hasil audit, tentang posisi DC-339 dan membandingkan Competitive Setting Profil dengan Company Alignment Profil. Pendekatan diskriptif kualitatif yang dikuantitatifkan. Data penelitian kuesioner-respon terdapat dalam interaksi di DC-399, yakni 20leader resonden. Hasil dari kuesioner berupa Competitive Setting Profil sebagai data primer yang menghasilkan competitive setting indek sebagai data sekunder, company alignment profile sebagai data primer yang menghasilkancompany alignment indek sebagai data sekunder. Dari sini menghasilkan Analisa yang bersifat kualitatif dan kuantitatifkan diukur dari pengecekan standar deviasi sebesar 0,5 sebagai tolak ukur persepsi dan tingkat pemahaman responden. Hasil penelitian ditemukan competitive Setting Index per responden dengan standar deviasi 0,6 dan 0,7 kesimpulan bahwa persepsi dan pemahaman responden relative tidak sama dan company alignment index per responden standar deviasi 0,6 ksimpulan bahwa persepsi dan pemhaman hampir sama. Sedangkan CSI rata-rata 4,8 dgn standar deviasi 0,4; informationalized 4,2 dengan standar deviasi 0,2 ;empowered 4,4 standar deviasi 0.1 general 3,8 standar deviasi 0,3; aggressiveness 4 standar deviasi 0,3; ccapability 3,7 standar deviasi 0; economic 3,5 standar deviasi o; technology 3,5 standar deviasi 0; social 4 standar deviasi 0,1; CSI sebesar 4 sd 0,2. Targeting 4,3 sd 0,1; positioning 4,6 sd 0; differentiation 4,3 sd 0; marketing mix 4.3 sd 0 ; selling 3,8 sd 0; brand 4 sd 0; service 4,5 sd 0; process 4,6 sd 0; CAIsebesar 4,3 sd 0 . Hasil perbandingan CSI lebih kecil dari CAI menginterprestasikan DC-399 berada posisi market driven menujucostomer driven. Saran untuk DC-399 yaitu 1. Harus menyiapkan diri secepatnya agar tidak ketinggalan perubahan tersebut yang mengakibatkan kehancuran network 2. Menambah pengetahuan dan ketrampilan yang dirasa kurang pada diri leader 3. Strategi duplikasi harus lebih ditekankan terhadap downline agar tetap mampu unggul dalam kompetisi.
\end{abstract}

Kata Kunci: Network, competitif setting profil, company alignment profil

\section{PENDAHULUAN}

Multi level marketing merupakan salah satu dari berbagai cara yang dapat dipilih oleh sebuah perusahaan untuk memasarkan/mendistribusikan produknya. Pada pelanggan eceran dengan memberdayakan distributor independent untuk melaksanakan tugas pemasaran produk melalui pengembangan armada pemasaran/penjual langsung secara mandiri tanpa campur tangan perusahaan. Target penjualan sepenuhnya ditentukan oleh distributor independent dan jaringan penjual langsung yang dikembankan. Wirausaha/entrepreneur saja masih belum cukup melainkan harus menuju dan menjadi ultrapreneur/ultra usaha. Ubud salim 
(1992:2). Daya Tarik multi level marketingmnimnya resiko keuangan yang harus ditanggung apabila gagal.

Audit pemasaran melainkan sebagai suatu reaksi dari penurunan kinerja dan penjualan, dalam kaitannya dengan peningkatan jenjang karier di forever young Indonesia. Dan sebagai tolak ukur menentukan strategi jangka Panjang agar tetap survive.

Tabel 1. The Strategic Marketing Plus 2000 Conceptual Framework

\begin{tabular}{|c|c|c|c|c|c|}
\hline Nilai & 1 & 2 & 3 & 4 & 5 \\
\hline Company & Producer & Seller & Marketer & Specialist & Service Provider \\
\hline $\begin{array}{l}\text { Type of } \\
\text { Company }\end{array}$ & $\begin{array}{c}\text { Production } \\
\text { Oriented }\end{array}$ & $\begin{array}{l}\text { Selling } \\
\text { Oriented }\end{array}$ & $\begin{array}{l}\text { Marketing } \\
\text { Oriented }\end{array}$ & Market Driven & Costomer Driven \\
\hline $\begin{array}{l}\text { Key } \\
\text { Succesful } \\
\text { Factor }\end{array}$ & $\begin{array}{l}\text { - Operation } \\
\text { Efisiency } \\
\text { - Product } \\
\text { standardization } \\
\text { - Mass distribution }\end{array}$ & $\begin{array}{l}\text { - Persuasive } \\
\text { selling } \\
\text { - Product } \\
\text { featuring } \\
\text { - Mass } \\
\text { promotion }\end{array}$ & $\begin{array}{l}\text { - } \text { Market } \\
\text { effectiveness } \\
\text { - } \text { Product } \\
\text { differentiation } \\
\text { - } \text { Balance } \\
\text { promotion }\end{array}$ & $\begin{array}{l}\text { - Niche } \\
\text { selectivity } \\
\text { - Product } \\
\text { specialization } \\
\text { - Integrated } \\
\text { communication }\end{array}$ & $\begin{array}{l}\text {-1.Data base } \\
\text { accountability } \\
\text { 2.Product } \\
\text { costomization } \\
\text {-3. interactive } \\
\text { communication }\end{array}$ \\
\hline
\end{tabular}

Sumber : Hermawan Kertajaya, 1999

\section{TINJAUAN PUSTAKA}

\section{Penelitian Terdahulu}

Di maksudkan untuk memperoleh gambara dan kerangka pemikiran dari suatu penelitian selain itu juga untuk mengetahui perbedaan atau kesamaan antara hasil penelitian yang satu dengan yang lain, sehingga dapat terungkap variable-variabel yang terlepas dari pengamatan penelitian terdahulu.

Penelitian tentang Mu'amalah dan MLM, Tarmizi Yusuf (200) untuk membuka wawasan pembaca khususnya umat Islam dan umum, bahwa Islam mengajarkan dan membatasi dalam berbinis, bisnis MLM yang selama ini dianggap menipu dan menyengsarakan rakyat, itu tidak benar.

\section{Perencanaan Bisnis}

Philip Kotler $(1999 ; 80)$ perencanaan strategi berorientasi pada pasar adalah proses manajerial untuk mengembangkan dan mempertahankan kesesuaian terus menerus antara tujuan, ketrampilan dan sumber daya organisasi dengan peluang pasar yang terus berubah.

\section{BAURAN PEMASARAN}

Philip Kotler(1999) bauran pemasaran adalah seperangkat alat pemasaran yang digunakan perusahaan untuk mencapai tujuan pemasaran dalam pasar sasaran.

Saluran distribusi/penjual langsung adalah pemasaran costomer product secara langsung kepada konsumen umumnya di rumah penjual atau rumah orang lain di tempat kerja. 
Amerika Marketing Assosiaion/AMA (1994) pemasaran sebagai suatu proses perencanaan dan eksekusi mulai tahap konsepsi, penetapan harga, promosi hingga distribusi barang-barang, ide-ide, dan jasa-jasa untuk melakukan pertukaran yang memuaskan individu dan Lembaga-lembaganya. Waen J Keagen (1997) salah satu sifat yang menonjol dari saluran di negara berkembang adalah banyaknya orang yang terlibat dalam penjualan barang dagangan yang jumlahnya hanya sedikit. MLM merupakan suatu cara penjualan. Sebagaimana sebuah bisnis, MLM memenuhi persyaratan sebagai bisnis murni, yaitu bisnis pemasaran.

\section{Metode Pengendalian Pemasaran}

W. Edwards Deming (1997) motivasi adalah perubahan-perubahan yang sekarang dibutuhkan dalam kualitas berkaitan dengan bagaimana orang-orang dikelola dan dimotivasi - lebih banyak orang harus mempunyai kebangaan pada pekerjaan mereka. Sondang (1997) manusia dalam organisasi perlu diberikan motivasi yang tepat sehingga mereka bersedia memberikan kontribusi yang maximal demi keberhasilan perusahaan.

\section{Audit Pemasaran}

Amin tunggal,(1997) suatu audit pemasaran terdiri dari suatu tujuan yang independent obyektif yang menyeluruh tentang lingkungan pemasaran dan keadaan yaitu program pemasaran secara keseluruhan adalah hubungannya dengan organisasi, tujuan, strategi perencanaan dan system pendukung keputusan, program area fungsional dan produktifitas pemasaran secara keseluruhan untuk tujuan menentukan, bagaimana baiknya program pemasaran dilaksanakan dan bagaimana program pemasaran dapat diperbaiki. Kotler, Gregor dan Rodgers (dalam hermawan K. 1995) audit pemasaran adalah pemeriksaan terhadap suatu perusahaan atau unit bisnis secara komprehensif, sistematis, independen dan berkala.

\section{Konsep Marketing Plus 2000}

Ohmae (1983) dalam hermawan k. (1995) dalam bukunya the mindof the strategic menyebutkan bahwa ada 3 pedoman yang harus diperhatikanuntuk menyusun suatu strategi yaitu Company, Costomer, dan Competion.ketiga elemen ini secara kolektif disebut strategic triangle. Peter (1997) secara detail beragumen bahwa perubahan lingkungan bisnis harus benar-benar diperhatikan dalam penyusunan strategi, perubahan lingkungan bisnis semakin cepat, kompleks dan tak terduga.

\section{METODE PENELITIAN}

Penelitian dilakukan pada perusahaan Multi Level Marketing Forever Young DC399, leader DC-399 populasi 20 orang dan menjadi sampel. Ali Saukah (2000) populasi dan sampel tepat digunakan jika penelitian yang dilakukan mengambil 
sampel sebagai subyek penelitian. Akan tetapi jika penelitiannya adalah seluruh anggota populasi akan lebih cocok digunakan istilah subyek penelitian Experimental.

\section{Teknik Audit}

Menggunakan Teknik Ansof (1990) yang dimodifikasi Hermawan K. (1995) dalam Strategic Marketing Plus 2000 sbb:

1. Bila kedua form selesai diisi, langkah selanjutnya adalah menghitung nilai ratarata dari setiap profil yang didapat dari responden. Setelah menghitung per responden lalu menghitung secara keseluruhan responden. Hasil akhir akan memberikan yang dinamakan Competitive Setting Index yaitu index yang didapat dari hasil rata-rata Competitive Setting Profil dan Company Alignment Index dari hasil rata-rata Company Alignment Profil.

2. Membandingkan hasil total CSI dengan CAI:

1) Bila $C A I>$ CSI maka Positif.

2) Bila $C A I<C S I$ maka Negatif.

\section{TEMUAN DAN PEMBAHASAN}

Tabel 2. Competitive audit CSI score rata-rata dan standar deviasi

\begin{tabular}{lcc}
\hline \multicolumn{1}{c}{ Dimensi } & Score rata-rata & Standar deviasi \\
\hline Enlightened & 4,8 & 0,4 \\
Informationalized & 4,1 & 0,2 \\
Empowered & 4,4 & 0,1 \\
General & 3,8 & 0,3 \\
Aggressiveness & 4 & 0,3 \\
Capability & 3,7 & 0,0 \\
Economic & 3,5 & 0,0 \\
Technology & 3,5 & 0,0 \\
Social $\quad$ CSI & 4 & 0,1 \\
& $\mathbf{4}$ & $\mathbf{0 , 2}$ \\
\hline
\end{tabular}

Sumber : Data Sekunder, Spss 6.

Tabel 3. Competitive audit CAI score rata-rata dan standar deviasi

\begin{tabular}{|c|c|c|}
\hline Dimensi & Score rata-rata & Standar deviasi \\
\hline Segmentation & 4,4 & 0,2 \\
\hline Targeting & 4,3 & 0,0 \\
\hline Positioning & 4,6 & 0,0 \\
\hline Differentiation & 4,3 & 0,0 \\
\hline Marketing mix & 4,3 & 0,0 \\
\hline Selling & 3,5 & 0,0 \\
\hline Brand & 4,0 & 0,0 \\
\hline Service & 4,5 & 0,0 \\
\hline Process & 4,6 & 0,0 \\
\hline CAI & 4,3 & 0,0 \\
\hline
\end{tabular}

Sumber : Data Sekunder, spss 6.0 
Berdasarkan data tersebut diatas membandingkan CSI lebih kecil dari CAImenerangkan bahwa posisi DC-399 berada dalam posisi Market Driven sebesar 4,3 dan harus mempersiapkan diri ke Costomer Driven.

\section{KESIMPULAN DAN SARAN}

Berdasarkan hasil perhitungan $C A I>C S I$ harus mempersiapkan diri sehingga mampu memenangkan kompetisi yang semakin ketat.

The Strategic Marketing Plus 2000 conceptual Framework, key successful factors sebagai berikut :

1. Niche Selectivity merupakanniche yang terfokus dalam kaitan ini presentation yang dilakukan DC-399 harus focus.

2. Product Specialitation adalah pembebanan ada pada berbagai seminar dan motivasi yang diadakan oleh pusat.

3. Integrated Communication merupakan komunikasi yang terpadu diarahkan pada pembentukan nilai, sebagai manifestasi dari misi perusahaan yaitu "Mencintai dan Melayani".

Namun demikian penelitian ini memiliki sejumlah keterbatsan obyek yang diteliti merupakan keterbatasan yang fundamental. Penelitian ini bersifat ekperimental.

\section{DAFTAR PUSTAKA}

Arikunto, Suharsimi. 1996. Prosedur Penelitian. Jakarta: Menaker Maju

Belu, Wilfridus. "Organizational Network." Dalam Majalah Usahawan Indonesia. No.02 th.XXVIII. Februari1998. Jakarta : BPFE - UI

Direct Selling Assotiation. 1998."Code of Ethics, The Direct Selling Industry, AS Amended by Board of Directors Through, Desember 8, 1998." In Derect Selling. In http://www.yahoo.com.

Fahmiyani, Layinatul. 2000." Pelaksanaan Audit Pemasaran di Perusahaan Songkok Awing dan Songkok Gresik." Dalam Skripsi tidak diterbitkan Malang : FE UMM.

Goni, Roy." Distribusi Strategi Pemasaran dan Peta Distribusi." Dalam Majalah Usahawan Indonesia. No.02 Th.XXVIII. Februari 1998. Jakarta :BPFE - UI.

Harefa, Andrias. 1999. Pesona Bisnis Direcct Selling dan Multi Level Marketing. Jakarta: Gramedia Pustaka Utama.

Jebarus, Felix. " anatomi Sistem Distribusi di Indonesia." Dalam Majalah Usahawan Indonesia.No.02 Th. XXVIII. Februari 1998. Jakarta:BPFE - UI.

Jensen, Dan. 1996." Compezation Plan Types, Evaluating Network Marketing Opportunities." In Multi Level Marketing. In Birmingham :http://www.Yahoo.com 
Kartajaya, Hermawan." Audit Pemasaran Berdasarkan Strategi Marketing Plus 2000." Dalam Kelola.No.8/IV/1995. Yogyakarta : UGM .1996.Marketing plus 3. Jakarta: Pustaka Sinar Harapan.

.1999. Marketing plus 2000, Siasat Memenangkan Persaingan Global. Jakarta: PT. Gramedia Pustaka Utama.

Kotler, Philip. 1995. Manajemen Pemasaran Analisis, Perencanaan, Implementasi. Edisi VII. Jilid I. Jakarta : Salemba Empat. . 1997.Manajemen Pemasaran, Analisis, Perencanaan, Implementasi dan Kontrol. Edisi Bahasa Indonesia. Jilid I. Jakarta : prentice Hall.

Keegan, Warren J. 1997. Manajemen Pemasaran Global. Jilid II. Jakarta : Premalindo.

Keraf, Sonny.1998. Etika Bisnis, Tuntunan dn Relevansinya. Edisi Baru. Yogyakarta : Kanisius.

Liem, KG. 1999. "Marketing Plan." Dalam Business Kit Forever Young Indonesia.Jakarta : PT. Forever Insan Abadi.

Mulyadi. 1998. Total Quality Manajemen, Prinsip Manajemen Kontemporer untuk Mengarungi Bisnis Global.Yogyakarta : Aditya Media UGM.

M, Teguh Pudjo. 1999. Aplikasi Manajemen Audit dalam Industri Perbankan. Edisi Pertama. Yogyakarta : BPFE.

Siagian, Sondang P. 1998. Manajemen Strategic. Cetakan Kedua. Jakarta : Bumi Aksara.

Salim, Ubud. 1999. Bisnis Kecil/Menengah Kunci Utama Indonesia Menghadapai Krisis Kewiausahaan PerusahaanSudut Pandang Manajemen Bisnis." Dalam Makalah Seminar Regional Sehari. PPI UNIBROW. Malang, 21 Oktober 1999.

Saukah, Ali et al. 2000.Pedoman Penulisan Karya Ilmiah: Skripsi, Tesis, Dsertasi, Artikel, Makalah, Laporan Penelitian. Edisi Keempat. Malang : Universitas Negri Malang.

Suwarso, 1994. Manajemen Strategi konsep Alat Analisa dan Konteks. Edisi Pertama. Yogyakarta : UPP AMP YKPN.

Tunggal, Amin Widjaya. 1992. Manajemen Audit suatu Pengantar.Jakarta:PT. Rineka Cipta.

. 1992. Audit pemasaran. Jakarta:PT Rineka Cipta.

. 1995. Audit Manajemen Kontemporer. Jakarta: Harvindo.

Tjipto, Fandy.1999. Strategi Pemasaran. Edisi 2. Yogyakarta:Andi Yogya.

Umar, Husein. 1996. Metode Penelitian Untuk Skripsi dan Tesis.Jakarta : Bisnis Raya Gitafindo Persada.

Yusuf, Trmizi. 2000. Strategi Multi Level Marketing Secara cerdas dan Halal, Peluang Bisnis Kontriversial yang Berkembang Pesat.Jakarta : PT. Elex Komputindo Gramedia. 